\title{
The tumor microenvironment in prostate cancer: elucidating molecular pathways for therapy development
}

This article was published in the following Dove Press journal:

Cancer Management and Research

24 July 2012

Number of times this article has been viewed

\author{
Paul G Corn \\ Department of Genitourinary Medical \\ Oncology, MD Anderson Cancer \\ Center, Houston, TX, USA
}

\begin{abstract}
Mechanisms leading to the development of virulent prostate cancer are not confined to the cancer epithelial cell, but also involve the tumor microenvironment. Multiple signaling pathways exist between epithelial cells, stromal cells, and the extracellular matrix to support tumor progression from the primary site to regional lymph nodes and distant metastases. Prostate cancers preferentially metastasize to the skeleton, prompting considerable research effort into understanding the unique interaction between prostate cancer epithelial cells and the bone microenvironment. This effort has led to the discovery that signaling pathways involved in normal prostate and bone development become dysregulated in cancer. These pathways stimulate excessive cell growth and neovascularization, impart more invasive properties to epithelial cells, weaken antitumor immune surveillance, and promote the emergence of castrate-resistant disease. An improved understanding of the complex relationship between cancer epithelial cells and the organ-specific microenvironments with which they interact has created a powerful opportunity to develop novel therapies.
\end{abstract}

Keywords: prostate cancer, molecular signaling, prostate cancer therapy, tumor microenvironment, castrate-resistant prostate cancer

\section{Introduction}

For men in the United States and Europe, prostate cancer is the most commonly diagnosed nonskin cancer. ${ }^{1-3}$ In the United States, prostate cancer accounts for $11 \%$ of cancer-related deaths in males, ranks second as a cause of cancer mortality in men, and incurs significant healthcare costs. ${ }^{1,4,5}$ If the tumor is organ-confined at the time of diagnosis, prognosis is often favorable and treatment is curative for many patients. ${ }^{6,7}$ In contrast, metastatic prostate cancer portends a much worse prognosis. ${ }^{7}$ Prostate cancers preferentially metastasize to the skeleton, and associated complications including bone pain, pathological fractures, and spinal cord compression are responsible for much of the morbidity of the disease. ${ }^{8}$ The presence of bone metastases also confers a 5 -year survival rate of only $25 \%$ and a median survival of approximately 40 months. ${ }^{8}$ Prostate cancer cells are typically derived from the prostate epithelium and receive stimulation via the androgen receptor (AR) for continued proliferation and survival. ${ }^{9,10}$ For this reason, the initial treatment for metastatic or advanced prostate cancer is androgen deprivation therapy, consisting of either surgical (ie, orchiectomy) or medical castration (with luteinizing hormone-releasing analogs or antagonists). ${ }^{11}$ Although androgen deprivation therapy is usually effective when initially used, relapse occurs after a median of 18-24 months with the appearance of castrate-resistant prostate cancer (CRPC). ${ }^{12}$
Correspondence: Paul G Corn MD Anderson Cancer Center, Department of Genitourinary Medical Oncology, Unit 1374, I5I5 Holcombe Boulevard, Houston, TX 77030, USA

Tel +l 7/35637208

Fax + I 7/35630099

Email pcorn@mdanderson.org 
A notable feature of the castrate-resistant phenotype is that, paradoxically, tumors continue to rely on androgen signaling for growth despite undetectable levels of circulating testosterone in blood. ${ }^{13,14}$ This occurs through a shift in reliance of the tumor on androgen endocrine sources (ie, gonads and adrenal glands) to autocrine/paracrine sources produced locally within the tumor microenvironment. ${ }^{15}$ The detection of intratumoral androgen levels is now being incorporated into clinical research studies, but is not yet a standardized test. Importantly, intratumoral androgens can be inhibited by novel small-molecule therapeutics. For example, the drug abiraterone, which potently inhibits both endocrine and autocrine/paracrine testosterone biosynthesis by blocking the activity of the enzyme cytochrome P450 CYP $17,{ }^{16}$ has been shown to improve survival in men with metastatic CRPC (mCRPC) after failure of the chemotherapeutic agent docetaxel. ${ }^{17}$

Other treatment options for patients with mCRPC include cytotoxic chemotherapies and vaccine-based approaches. Both docetaxel and cabazitaxel have been shown to prolong survival in patients with mCRPC in randomized phase III studies. ${ }^{18,19}$ Presently, docetaxel remains the standard first-line therapy, followed by cabazitaxel in the second-line setting for patients whose cancers have progressed after receiving docetaxel therapy. ${ }^{11}$ The autologous cancer vaccine, sipuleucel-T, was also approved in 2010 after it was shown to improve survival in patients with minimally symptomatic mCRPC. ${ }^{11,20}$

Despite considerable progress in the development of novel androgen-ablative, cytotoxic, and immunologic therapies, mCRPC remains incurable, and better treatments are needed. An improved understanding of the cellular and molecular mechanisms involved in prostate cancer progression has led to an increasing number of new anticancer drugs under development for the treatment of this disease. ${ }^{21}$ Within the cellular microenvironment, molecular signaling between the tumor cells and surrounding cells that contribute to cancer growth are emerging as critical therapy targets. This review discusses the three principal tumor microenvironments involved in prostate cancer progression: the prostate gland, lymph node, and bone microenvironments; signaling pathways that impact the tumor microenvironment; and novel agents that modulate these pathways for potential therapy.

\section{Tumor microenvironments}

Tumors are no longer regarded as isolated masses of aberrantly proliferating epithelial cells. Rather, their properties depend on complex interactions between cancer epithelial cells and the surrounding stromal compartment within the tumor microenvironment. The stromal compartment is comprised of multiple nonmalignant cells such as fibroblasts, myofibroblasts, endothelial cells, and immune cells; growth factors; chemokines; cytokines; extracellular matrices (ECMs); and matrix-degrading enzymes. ${ }^{22,23}$ Crosstalk between the epithelial and stromal compartments promotes tumor progression by mechanisms such as remodeling ECM to enhance invasion, releasing soluble growth factors necessary for castrate-resistant growth, and stimulating angiogenesis. ${ }^{24,25}$ Surrounding tumor stromal cells, while not having the marked genetic instability of tumors, have been shown to undergo genetic alteration in response to the presence of a tumor; these may further sustain the malignant phenotype. ${ }^{26-28}$

Prostate cancer has a prolonged natural history that can be conceptually divided into three stages. The first and most prolonged stage involves the initiation and development of organ-confined disease, estimated to take more than 15 years. ${ }^{29}$ The second stage involves spreading into regional lymph nodes, and the third stage involves metastatic dissemination via both the lymphatic and blood circulations to the skeleton. ${ }^{29}$ Each of these stages represents a unique tumor microenvironment in which the prostate cancer epithelial cells survive, adapt, and proliferate. ${ }^{29}$

\section{Prostate gland microenvironment}

The normal prostate gland consists of prostatic ducts lined with epithelium and a stroma that consists mainly of smooth muscle cells with smaller numbers of fibroblasts, endothelial cells, and nerve cells. ${ }^{22}$ In addition to their expression in epithelial cells, ARs are also abundantly expressed on multiple cell types in the normal prostate stroma, including smooth muscle cells and endothelial cells. ${ }^{30}$ During normal development, prostate epithelial cells depend on signals from the stroma for migration and organ homeostasis. ${ }^{30}$ In turn, signals from epithelial cells to prostate stromal cells appear to be required to maintain smooth muscle differentiation. ${ }^{30,31}$

In prostate cancer, stromal cells demonstrate an altered phenotype in which there is increased ECM remodeling, increased protease activity, increased angiogenesis, and an influx of inflammatory cells. ${ }^{32}$ These cancer-activated stromal changes resemble the tissue alterations that accompany normal wound healing. ${ }^{32}$ Altered stromal fibroblasts (referred to as myofibroblasts) present in both cancer and wound healing are morphologically distinct from normal fibroblasts and acquire some of the properties of smooth muscle cells, ${ }^{23,25,33}$ including expression of vimentin and smooth muscle $\alpha$-actin. ${ }^{24}$ While myofibroblasts participate in the formation 
of granulation tissue during normal wound healing, ${ }^{24,34,35}$ in tumors, they promote stromal reactivity and tumor cell proliferation..$^{35,36}$ The importance of myofibroblasts is evidenced by their appearance within carcinoma in situ lesions of different epithelial tumors, suggesting they participate in early tumorigenesis. ${ }^{25}$ In prostate cancer, myofibroblasts are detectable in the tissues surrounding the foci of prostate intraepithelial neoplasia, and myofibroblast activity increases with increasing prostate tumor grade. ${ }^{37}$

Experimental studies demonstrate that myofibroblasts are not merely a passive reaction to the tumor, but also a source of signals that enhance tumorigenicity. For example, coculture experiments have shown that tumor-associated myofibroblasts stimulate growth and tumor formation from nontumorigenic prostate cell lines. ${ }^{38,39}$ Conversely, it has been found that nonactivated fibroblasts can promote the reversion of tumor cells to a more differentiated and slower-growing phenotype. ${ }^{40}$ Other effects of myofibroblasts relevant to tumor progression include remodeling of the ECM, tumor neovascularization (angiogenesis), and the development of immunological tolerance to the tumor. ${ }^{34}$

\section{Lymph node microenvironment}

Based on personal experience with numerous clinical trials at University of Texas MD Anderson Cancer Center (Houston, $\mathrm{TX}$ ), radiographically enlarged lymph nodes are detected in only roughly $20 \%$ of patients with metastatic disease. Interestingly, however, molecular-pathologic analysis of lymph nodes from surgical specimens and autopsy studies suggest that nodal involvement without enlargement occurs much more frequently. ${ }^{41,42}$ The fact that a majority of prostate cancers spread to regional lymph nodes, but only a minority of nodes are pathologically enlarged, suggests that lymph nodes are not a preferred microenvironment for prostate cancer growth. Thus, while lymphadenopathy is an independent adverse prognostic indicator in prostate cancer, clinical sequelae from lymphadenopathy are relatively uncommon. ${ }^{43}$

However, it has been postulated that because tumor cells within lymph nodes have disseminated from the original site of the cancer, these cells may possess a higher metastatic potential. In support of this, lymph node metastases show a relatively greater loss of cell adhesion molecules than primary tumors. ${ }^{44}$ This phenomenon may be explained by epithelialto-mesenchymal transition, a biologic process that commonly occurs during both normal embryogenesis and cancer progression when epithelial cells assume characteristics of mesenchymal cells, including greater migratory and invasive properties. ${ }^{45,46}$ A significant association also exists between vascular endothelial growth factor (VEGF) activity and the presence of lymph node metastases, suggesting a requirement for angiogenesis during prostate cancer tumor dissemination. ${ }^{47}$ Interestingly, although the association between lymphangiogenesis (formation of new lymph vessels) and lymph node metastases is less clear, ${ }^{47}$ lymphangiogenesis can occur in the absence of tumor involvement. ${ }^{48}$ These data suggest that the primary tumor acts as a source of soluble stimuli (mainly growth factors in the VEGF family) that "prepare" the lymph node microenvironment for subsequent tumor involvement. $^{47}$

\section{Bone microenvironment}

The propensity of prostate cancer to metastasize to bone is one of the most striking examples of microenvironmentdependent tumor progression in human cancer. ${ }^{8}$ The bone microenvironment has become an important focus of basic and clinical research efforts. In contrast to most other solid tumors that demonstrate osteolytic lesions (eg, breast and lung), prostate cancer bone metastases are typically osteoblastic. ${ }^{49}$ Osteoblastic lesions are "bone-forming" lesions that occur through the remodeling of bone matrix by osteoblasts and osteoclasts. In normal bone, a continuous process of bone turnover maintains structural homeostasis through a dynamic balance between osteoblastic and osteoclastic activities. In prostate cancer, this balance is disrupted when prostate cancer epithelial cells express bone-specific proteins and soluble osteoblastic growth stimulatory factors that lead to the production of abnormal, unstructured bone. ${ }^{49}$ For example, prostate cancer cells produce bone morphogenetic protein, $\beta 2$ microglobulin, osteocalcin, bone sialoprotein, endothelin-1 (ET-1), transforming growth factor- $\beta$ (TGF- $\beta$ ), VEGF, parathyroid hormone-related protein, and insulin-like growth factor- 1.49 Expression of many of these proteins is typically restricted to bone cells, but during prostate cancer progression, these proteins become aberrantly expressed by cancer epithelial cells, a phenomenon referred to as "osteomimicry."49-51

Another stromal pathway usurped by prostate cancers is the receptor activator of nuclear factor $\kappa \beta$ (RANK) ligand pathway. ${ }^{22}$ RANK ligand is normally expressed by osteoblasts and other stromal cells and functions in order to regulate osteoclastic activity by binding to RANK receptors on preosteoclasts, and stimulating them to mature into osteoclasts. ${ }^{8,52,53}$ In prostate tumors, RANK ligand is either overexpressed directly by the tumor or induced indirectly through tumor activation of osteoblasts. ${ }^{22}$ This event prompts an endless loop of increased bone turnover and increased tumor metastatic ability that may account for the central 
role of bone metastases in advanced prostate cancer. ${ }^{22,52}$ At the same time that prostate cancer epithelial cells induce tumor-promoting changes in the tumor microenvironment, prostate cancer epithelial cells may respond to growth factors secreted by osteoblasts and also present in bone matrix. Growth-promoting effects on prostate cancer epithelial cells have been demonstrated with conditioned medium from cultured osteoblasts ${ }^{54-56}$ and in three-dimensional culture systems. ${ }^{57}$ Interleukin- 6 produced by osteoblasts (and by osteomimetic prostate cancer cells) is a cytokine important in normal bone turnover and has been shown to induce prostate cancer cell proliferation and induction of androgen-regulated genes normally dependent on the AR. ${ }^{55,58}$ Prostate cancer cells cultured in decellularized bone matrix show induction of genes regulating migration and invasive potential, suggesting that the bone matrix is also a significant source of growth factors. ${ }^{59}$ All of these events further promote a chain of events leading to prostate cancer bone metastases. ${ }^{22}$

\section{Pathways for therapy development}

Several classes of novel therapies that disrupt signaling pathways within tumor microenvironments are currently under investigation (Table 1). In contrast to cytotoxic therapies that principally target the epithelial cell (regardless of its anatomic location), these agents disrupt the "crosstalk" between epithelial cells, stromal cells, and the ECM necessary for prostate cancer progression and metastases. Since skeletal metastases are the principal cause of morbidity and mortality from prostate cancer, the majority of clinical trials evaluating novel therapies enroll patients with advanced disease. Thus, the bone tumor microenvironment is most often being evaluated. There is emerging evidence, however, that high-risk localized tumors (ie, those tumors with a high chance of micrometastatic spread to lymph nodes) acquire the osteomimetic characteristics of skeletal metastases..$^{15,49}$ To test the hypothesis that signaling pathways involved in the development of high-risk localized disease are shared with skeletal metastases, there are a growing number of neoadjuvant trials for high-risk patients.

The first class of therapeutic agents to support the hypothesis that targeting the tumor microenvironment could benefit patients clinically is radiopharmaceuticals. Radiopharmaceuticals (eg, strontium-89, samarium-153, rhenium-186, and radium-223) concentrate at sites of bone-forming activity to deliver a potent dose of radiation. Radiopharmaceuticals have consistently been shown to palliate bone pain, and in some studies have demonstrated a survival benefit. ${ }^{60}$ This benefit is attributed not only to a direct cytotoxic effect on cancer epithelial cells, but also the suppression of pathologic osteoblast and osteoclast activities (ie, suppression of the chain of events). Despite their success, radiopharmaceuticals lack target specificity, as evidenced by dose-limiting side effects such as bone marrow suppression. The novel small-molecule and immune-based therapeutics discussed below have the potential to provide greater efficacy, specificity, and safety.

\section{Targeting signaling pathways mediated by cell adhesion proteins}

The ECM is made up of many types of macromolecules, and plays an important role in maintaining normal cellular behavior and tissue architecture. Cell adhesion molecules and tight junction proteins on cell surfaces (eg, $\beta 1$ integrins and E-cadherin) maintain cell-cell contacts and contact with the ECM..$^{23,61}$ Gap junctions allow passive diffusion of small signaling molecules between adjacent cells. ${ }^{61} \mathrm{In}$ normal tissues, the basement membrane, a specialized form of ECM, separates the epithelium from stromal cells. ${ }^{23}$ The ECM is essential for maintaining cell shape and behavior, and for maintaining the correct polarity of epithelial cells by establishing basal and apical surfaces ${ }^{61}$ Correct function of cell adhesion is necessary for organ homeostasis and, additionally, has been shown to be important in suppressing tumor formation. ${ }^{61}$ In contrast, alterations in the ECM occur in tumorigenesis and can profoundly affect the malignant potential of epithelial cells.

The integrins have attracted much interest as potential therapeutic targets in cancer. Patterns of integrin expression are characteristically altered in prostate tumors, with marked changes in subunit composition. ${ }^{44,62}$ Integrins become distributed over the entire cell surface through disruption of their normal localization on the basal surface. ${ }^{25,44}$ Integrins signal by recruiting focal adhesion kinase and Src kinase. These, in turn, activate components that affect cell growth, adhesion, motility, and cell survival. ${ }^{25,63}$ Of these, the focal adhesion kinase-Src complex is important in promoting angiogenesis and protease-associated tumor metastasis. ${ }^{63}$ Several integrin inhibitors, including the peptide cilengitide as well as integrinblocking monoclonal antibodies CNTO 95 and MEDI-522, are in clinical development for prostate cancer. ${ }^{62}$

\section{Targeting signaling pathways mediated by myofibroblasts}

Myofibroblasts present in cancer-activated stromal tissue are the source of many of the signals that direct tumor cell proliferation and survival. ${ }^{25,33}$ The importance of stromal cells in tumor progression has been demonstrated in coculture 
experiments. ${ }^{39,64}$ For example, the fibroblast growth factor signaling pathway (FGF/FGF receptor) mediates communication between prostate epithelium and stromal cells, including myofibroblasts. ${ }^{25,65}$ Signaling via FGF/FGF receptor leads to downstream activation of other prosurvival signal transduction pathways, including extracellular signal-regulated kinase, mitogen-activated protein kinase, and phosphatidylinositol 3-kinase/Akt. ${ }^{65}$ Signaling via phosphatidylinositol 3-kinase/Akt has been shown to have synergistic effects with AR signaling in the prostate epithelium. ${ }^{65}$ Small-molecule kinase inhibitors such as SU5402 and dovitinib (TKI258), which inhibit FGF/FGF receptor signaling, may have potential as anticancer agents. ${ }^{25}$

\section{Targeting signaling pathways mediated by the AR}

Several mechanisms are responsible for the castrate-resistant phenotype. ${ }^{66,67}$ One mechanism involves sensitization of the AR to lower levels of androgen present within tumors. This "androgen hypersensitivity" can occur from either a mutation at the ligand-binding site of the AR or from amplification of the gene encoding the AR. A second mechanism involves mutations in the AR that result in reduced ligand specificity. ${ }^{66}$ These mutated "promiscuous" ARs can be inappropriately activated by estrogens, progestins, growth factor tyrosine kinases, and other oncogenic signaling molecules. ${ }^{66,68} \mathrm{~A}$ third mechanism involves ligand-independent activation of AR signaling. A variety of cytokines and growth factors present in bone and prostate microenvironments have the ability to directly activate $\mathrm{AR}$ in this manner, including insulin-like growth factor, keratinocyte growth factor, epidermal growth factor, and interleukin-6. ${ }^{67,68}$ Finally, a fourth mechanism involves truly AR-independent pathways. In these cases of castrate-resistant disease, there is often a complete loss of AR expression. Tumor progression is then sustained by entirely new growth-promoting pathways, including overexpression of B-cell lymphoma 2 and/or activation of Akt. ${ }^{66,67}$

Several agents have been developed to overcome these different mechanisms of castrate resistance. TAK-700, a novel cytochrome P450 CYP17 inhibitor, depletes intratumoral androgens to overcome AR hypersensitivity and AR promiscuity (upstream progestins are also inhibited). The investigational AR antagonist, MDV3100, blocks nuclear translocation and DNA binding of the AR and thus may prevent ligand-independent activation of the AR. Oblimersen sodium, an antisense oligonucleotide that targets B-cell lymphoma 2 , initially exhibited promise in combination with docetaxel, as a therapy designed to overcome AR-independent survival pathways in mCRPC. ${ }^{67}$ However, this therapeutic combination failed to meet the primary endpoints (prostatespecific antigen response, $>30 \%$; major toxic event rate, $<45 \%$ ) of a phase II study suggesting limited utility. ${ }^{69}$

\section{Targeting crosstalk between cancer epithelial and stromal cells}

\section{Endothelin A receptor ET-I antagonists}

Atrasentan is an antagonist of the endothelin A receptor ET-1 and has been studied in clinical trials for the treatment of CRPC for both metastatic disease and biochemical relapse with rising prostate-specific antigen only. ${ }^{70,71}$ Although atrasentan did not reduce the risk of disease progression in either disease state, it has demonstrated favorable effects on bone biomarkers (eg, reduction in bone-specific alkaline phosphatase), stimulating continued interest in blocking ET-1 as therapy for patients with advanced disease. ${ }^{71}$ A second ET-1 antagonist, zibotentan (ZD4054), had shown a survival advantage in the treatment of patients with symptomatic mCRPC, but in a phase III trial that evaluated zibotentan added to the standard of care in 594 patients with MCRPC, there was no significant improvement in the primary endpoint of OS. ${ }^{72}$ Denosumab, a monoclonal antibody against RANK ligand, has recently been shown to reduce skeletal-related events in patients with mCRPC. ${ }^{73}$

\section{Src kinase inhibitors}

Src kinase is a nonreceptor kinase of considerable importance in prostate cancer progression. Src, an essential downstream signal transducer for many cell surface receptors, including epidermal growth factor receptor, platelet-derived growth factor receptor, VEGF receptor, c-Met, and integrins, is of specific importance in the regulation of bone homeostasis. In vitro and in vivo experiments with osteoblasts and osteoclasts with targeted disruptions of Src suggest that this kinase may function by positively regulating osteoclasts and negatively regulating osteoblasts. ${ }^{74}$ Aberrant expression and/or activity of Src kinases occur in many advanced-stage tumors, including prostate cancer. ${ }^{74,75}$ Interestingly, elevated Src activity is correlated with decreased AR activity in prostate tumor specimens, further supporting a role for Src in the development of castration resistance and the potential benefit of utilizing Src inhibitors for therapy of advanced disease. ${ }^{76}$

Tyrosine kinase inhibitors active against Src are being studied for the treatment of mCRPC. Three dual Src/Bcr-Abl (breakpoint cluster region-Abelson) inhibitors are currently under clinical development, ${ }^{8}$ and dasatinib monotherapy has been shown in phase II studies to demonstrate a favorable 
effect on preventing progression of bone metastases and decreasing markers of bone metabolism. ${ }^{71,77}$ A randomized, phase III study comparing docetaxel with or without dasatinib in patients with $\mathrm{mCRPC}$ has now completed enrollment, and data are pending. ${ }^{78}$ Two other dual Src/Bcr-Abl (breakpoint cluster region-Abelson) inhibitors, saracatinib (AZD0530) and bosutinib (SKI-606), are in early stage evaluation for the treatment of prostate cancer bone metastases. ${ }^{8}$

\section{TGF- $\beta$ inhibitors}

TGF- $\beta$ has multiple functions which can be classified as either growth promoting or growth suppressive, depending on the tissue and cellular context. ${ }^{79}$ Experiments with conditional inactivation of its receptor, T $\beta$ RII, show that stromal cells (fibroblasts) require TGF- $\beta$ in order to exert their normal effects in suppressing epithelial proliferation. ${ }^{80}$ In benign prostate epithelium, TGF- $\beta$ maintains cellular differentiation, inhibits cell proliferation, and induces cell cycle arrest and/or apoptosis. ${ }^{81}$ Stimulation of fibroblasts by TGF- $\beta$ induces genes specific for tissue remodeling, including myofibroblast-related factors, ECM remodeling factors, and growth factors. ${ }^{82}$ In prostate epithelium, crosstalk between TGF- $\beta$ and AR is necessary for cellular apoptosis in response to androgen withdrawal. ${ }^{79,83}$ Although TGF- $\beta$ maintains physiologic homeostasis in normal tissues, its growthpromoting effects predominate in the malignant state.

TGF- $\beta$ is frequently upregulated in cancer cells, and it has been proposed that this, in turn, leads to the differentiation of fibroblasts to myofibroblasts and other properties of reactive stroma. ${ }^{24}$ Other tumorigenic effects ofTGF- $\beta$ include neovascularization, ECM degradation, and suppression of tumor-specific immune responses. ${ }^{81}$ In established prostate tumors, stromal cell promotion of tumor growth has been shown to be dependent on the presence of TGF- $\beta$ signaling. ${ }^{82}$ An important role of TGF- $\beta$ is also suggested by evidence that serum levels of TGF- $\beta$ are usually elevated in patients with advanced prostate cancer. ${ }^{81}$

Several approaches to inhibiting TGF- $\beta$ signaling are presently being developed. These include monoclonal antibodies, antisense oligonucleotides, and small-molecule tyrosine kinase inhibitors. All have demonstrated high activity in preclinical models of prostate cancer, and are expected to enter human clinical trials in the near future. ${ }^{81}$

\section{Angiogenesis inhibitors}

Angiogenesis is the process of new blood vessel formation. In normal tissues, angiogenesis occurs during growth, development, and wound repair. Angiogenesis is required by all solid tumors to sustain the expanding tumor mass. ${ }^{84}$ The tumor and stroma promote angiogenesis primarily through ligandreceptor pathways mediated by soluble angiogenic factors. Examples of these include VEGF/VEGF receptor, FGF/ FGF receptor, platelet-derived growth factor/platelet-derived growth factor receptor, and TGF- $\beta /$ TGF- $\beta$ receptor. Although recent studies with two potent angiogenesis inhibitors - the anti-VEGF monoclonal antibody bevacizumab and the multityrosine kinase inhibitor sunitinib - failed to show any survival benefit in mCRPC, there is continued interest in developing these agents as therapy. For example, aflibercept (VEGF Trap) is a recombinant fusion protein of the extracellular domains of both VEGF receptor-1 and VEGF receptor-2 and the Fc portion of human immunoglobulin G1. ${ }^{7}$ Single-agent activity has been demonstrated in phase II trials in several cancer types. ${ }^{85-88}$ Clinical trials of combination chemotherapy with aflibercept are also underway. A phase III trial of aflibercept in combination with docetaxel and prednisone in men with mCRPC $^{89}$ has completed accrual and is pending final analysis. ${ }^{7}$ A phase III combination trial with irinotecan/fluorouracil/ folinic acid for second-line treatment of metastatic colorectal cancer has recently been reported. ${ }^{90,91}$ Other approaches to blocking tumor angiogenesis include cediranib (AZD-2171), a kinase inhibitor for all three VEGF receptors, undergoing clinical trials for a variety of cancer types. Interim results of a phase II study of cediranib combined with prednisone in mCRPC have demonstrated partial responses to therapy and evidence of tumor regression in many other patients. ${ }^{92}$

The drug lenalidomide has multiple effects that may contribute to its antitumor properties. Lenalidomide demonstrates antiangiogenic properties and also induces immunity through enhancing $\mathrm{T}$ cell stimulation and inhibiting regulatory $T$ cells. The immunomodulatory effects of lenalidomide are implicated in its efficacy against certain hematologic malignancies such as myelodysplastic syndrome, multiple myeloma, and chronic lymphocytic leukemia. Lenalidomide also has synergistic effects with docetaxel in preclinical models of prostate cancer..$^{93}$ Despite this, however, a phase III trial of lenalidomide plus docetaxel and prednisone in CRPC was discontinued in late 2011 due to lack of treatment benefit versus docetaxel and prednisone alone. ${ }^{94}$ Lenalidomide is still receiving attention as a possible adjuvant therapy to cancer vaccines in the treatment of prostate cancer. ${ }^{93}$

\section{Hepatocyte growth factor (HGF)/c-Met signaling inhibitors}

The c-Met receptor is present on most cell types. Activation by HGF, its only known ligand, transduces multiple activities 
Table I Therapeutic agents targeting the prostate cancer microenvironment

\begin{tabular}{|c|c|c|c|c|}
\hline $\begin{array}{l}\text { Targeting strategyl } \\
\text { microenvironment }\end{array}$ & $\begin{array}{l}\text { Molecular pathway } \\
\text { target }\end{array}$ & $\begin{array}{l}\text { Therapeutic } \\
\text { class }\end{array}$ & Agent & $\begin{array}{l}\text { Trial } \\
\text { phase* }\end{array}$ \\
\hline \multirow[t]{3}{*}{ Integrin signaling networks } & $\alpha_{v} \beta_{3}$ integrin & Humanized mAb & MEDI-522 & II \\
\hline & $\alpha_{v}$ integrin & $\mathrm{mAb}$ & Intetumumab (CNTO 95) & II \\
\hline & $\alpha_{\mathrm{v}} \beta_{3} \alpha_{\mathrm{v}} \beta_{5}$ integrins & $\begin{array}{l}\text { Antagonist of } \alpha_{v} \beta_{3} \text { and } \\
\alpha_{v} \beta_{5} \text { integrins }\end{array}$ & Cilengitide & II \\
\hline \multirow[t]{7}{*}{$\begin{array}{l}\text { Bone development } \\
\text { related pathways }\end{array}$} & Src-family kinases & $\begin{array}{l}\text { Small-molecule kinase } \\
\text { inhibitor }\end{array}$ & Dasatinib & III \\
\hline & & & Saracatinib (AZD0530) & ॥ \\
\hline & RANK ligand & $\mathrm{mAb}$ & Denosumab & III \\
\hline & Endothelin receptor & Selective antagonist & Atrasentan & III \\
\hline & & & Zibotentan & III \\
\hline & Hedgehog signaling & Smoothened antagonist & (vismodegib) GDC-0449 & $1 / I I$ \\
\hline & FGF family & FGF receptors & TKI258 & II \\
\hline \multirow[t]{2}{*}{ Androgen signaling } & CYPI7 & $\begin{array}{l}\text { Irreversible inhibitor } \\
\text { of CYPI7 }\end{array}$ & Abiraterone acetate & $\begin{array}{l}\text { Approved } \\
\text { in EU, US }\end{array}$ \\
\hline & $A R$ & Small-molecule AR antagonist & MDV3100 & III \\
\hline Signaling crosstalk & mTOR & Rapamycin analogs & Temsirolimus & II \\
\hline \multirow[t]{4}{*}{ with $A R$} & & & Everolimus & II \\
\hline & EGFR & $\begin{array}{l}\text { EGFR tyrosine kinase } \\
\text { inhibitor }\end{array}$ & Gefitinib & II \\
\hline & IGF receptor & $\mathrm{mAb}$ & CP-75I,87I & ॥ \\
\hline & & & Cixutumumab (IMC-AI2) & ॥ \\
\hline \multirow[t]{10}{*}{ Antiangiogenesis } & VEGF & $\mathrm{mAb}$ & Bevacizumab & III \\
\hline & & $\begin{array}{l}\text { Recombinant fusion } \\
\text { protein (VEGF Trap) }\end{array}$ & Aflibercept & III \\
\hline & $\begin{array}{l}\text { VEGF receptor (and other } \\
\text { RTKs such as PDGFR) }\end{array}$ & $\begin{array}{l}\text { Small-molecule inhibitors } \\
\text { of RTKs }\end{array}$ & Sunitinib & III \\
\hline & & & Sorafenib & ॥ \\
\hline & & & Imatinib mesylate & ॥ \\
\hline & & & PTK787 & II \\
\hline & & & Axitinib & II \\
\hline & $\begin{array}{l}\text { Endothelial cell } \\
\text { receptor CDI05 }\end{array}$ & $\mathrm{mAb}$ & TRCI05 & $1 / I I$ \\
\hline & Uncertain mechanism & & Thalidomide & III \\
\hline & & Thalidomide analog & Lenalidomide & III \\
\hline
\end{tabular}

Notes: *Most advanced phase trial(s) with agent. All stages are according to ClinicalTrials.gov.

Abbreviations: AR, androgen receptor; CYPI7, cytochrome P450 17; EGFR, epidermal growth factor receptor; EU, European Union; FGF, fibroblast growth factor; IGF, insulin-like growth factor; mAb, monoclonal antibody; mTOR, mammalian target of rapamycin; PDGFR, platelet-derived growth factor receptor; RANK, receptor activator of nuclear factor $\kappa \beta$; RTK, receptor tyrosine kinase; US, United States; VEGF, vascular endothelial growth factor.

in the cell, including motility, proliferation, survival, and morphogenesis. ${ }^{95}$ Of particular relevance, the c-Met pathway activates a program of cell dissociation, cell motility, and protease production, which can permit tumor cell invasion and cell scattering that may be linked to metastasis. ${ }^{96}$ Tumors of epithelial origin frequently overexpress c-Met, resulting in increased responsiveness to HGF produced by stromal cells. ${ }^{97}$ Mutations in the gene encoding c-Met, resulting in delayed downregulation of signaling, have been found in human cancers. ${ }^{96}$ Monoclonal antibodies against human HGF have been developed and shown to neutralize HGF in vivo and to have antitumor activity. ${ }^{96,98}$ A second agent, BMS-777607, which targets c-Met is currently in preclinical development. BMS-777607 is an orally available kinase inhibitor that selectively neutralizes HGF activity and abolishes its effect on cell scattering and motility. ${ }^{99}$ Also in clinical trials is cabozantinib (XL-184), a kinase inhibitor with dual specificity for c-Met and VEGF receptor-2. Results of a phase II clinical trial in patients with $\mathrm{mCRPC}$ and progressive disease have recently been reported in which cabozantinib was shown to produce overall disease control in many of the enrolled patients. ${ }^{100}$ Responses were characterized by reductions in pain and improvements in bone scans. ${ }^{100}$

\section{Agents that affect immunity}

Host immune responses are capable of suppressing tumors. Similar to other tumor types, prostate tumors become infiltrated by $\mathrm{T}$ lymphocytes, consistent with the initial stages of 
a cell-mediated immune response. ${ }^{101}$ However, this immune response is generally ineffective due to loss or downregulation of cell-surface major histocompatibility complex, ${ }^{102}$ or the secretion of immune-suppressive factors including TGF- $\beta$ and interleukin-10. ${ }^{101}$ Tumor stroma interactions may potentially affect the immune response. There is evidence that myofibroblasts act as a physical barrier between tumor cells and immune cells. ${ }^{34}$ In addition, TGF- $\beta$ has been shown to reduce the proliferation and repress the cytotoxic activity of CD8 T lymphocytes, and to inhibit natural killer cell function. ${ }^{103}$ Of particular relevance in prostate cancer, androgens have been shown to demonstrate an immunosuppressive effect, and an improvement in antitumor response occurs after androgen withdrawal therapy. ${ }^{104}$ It has been suggested that immunotherapy for prostate cancer may be most effective in patients with early-stage disease and/or with low tumor burden. This is because a slow-growing tumor allows for sufficient time to build an optimal immune response; for example, by booster vaccination. ${ }^{101}$ Several forms of immunotherapy are currently in development for prostate cancer. ${ }^{101}$ Monoclonal antibodies, such as ipilimumab, block cytotoxic T cell lymphocyte-associated protein 4, resulting in nonspecific $\mathrm{T}$ cell activation and enhanced antitumor immunity. Ipilimumab is presently being tested in both androgen-dependent and castrate-resistant metastatic disease. ${ }^{105,106}$ Other vaccines "prime" immunity against prostate tumors by incorporating whole cell vaccines (based on prostate cancer cell lines) that can be genetically engineered to secrete immunostimulatory cytokines. $\mathrm{GVAX}^{\circledR}$, perhaps the best studied of these, is a whole-cell vaccine consisting of allogeneic prostate cancer cell lines that have been transduced with granulocyte-macrophage colony-stimulating factor complementary DNA. While recently completed clinical trials failed to demonstrate survival benefit for GVAX in mCRPC, a second experimental vaccine based on similar cell lines but engineered to express interleukin- 2 and interferon- $\beta$, is also being studied in patients with mCRPC. ${ }^{101}$

Viral vectors based on vaccinia or fowlpox cause host cells to express modified prostate-specific antigen and immune costimulatory molecules, which then induce an antitumor immune response. PROSTVAC ${ }^{\circledR}$ contains a gene for prostate-specific antigen that has been modified to enhance its immunogenicity. In addition, it encodes three modified proteins involved in the T cell costimulation pathway. ${ }^{101}$ Another approach to therapeutic vaccines, autologous dendritic cell vaccines (such as the currently licensed sipuleucel-T), are used to stimulate the patient's dendritic cells with prostate-specific proteins in vitro. Reintroduced dendritic cells may then activate an effective $\mathrm{T}$ cell response capable of eradicating the tumor.

\section{Conclusion}

Experimental studies on the biological mechanisms of prostate cancer have revealed extensive signaling pathways that provide communication between cancer epithelial cells, stromal cells, and the ECM within tumor microenvironments. These signaling pathways are necessary for prostate cancer progression. Many novel therapeutic agents under development for prostate cancer are designed to counter these signaling pathways, including AR inhibitors, angiogenesis inhibitors, osteoclast inhibitors, stromal inhibitors, and vaccines. The promise of these therapies is improved efficacy, specificity, and safety. The recent approvals of abiraterone and sipuleucel-T illustrate the dividends of translational research and indicate real progress towards curing this disease.

\section{Disclosure}

Medical editorial assistance for the writing of this article was provided by Susan DePetris of Phase Five Communications Inc, funded by sanofi-aventis US LLC, A SANOFI Company. The author retained full editorial control over the content of the manuscript, and received no compensation from any party for their work.

\section{References}

1. American Cancer Society. Cancer Facts and Figures 2010. Atlanta, GA: American Cancer Society; 2010.

2. Jemal A, Siegel R, Xu J, Ward E. Cancer statistics, 2010. CA Cancer J Clin. 2010;60(5):277-300.

3. Ferlay J, Parkin DM, Steliarova-Foucher E. Estimates of cancer incidence and mortality in Europe in 2008. Eur J Cancer. 2010;46(4):765-781.

4. Roehrborn CG, Black LK. The economic burden of prostate cancer. BJU Int. 2011;108(6):806-813.

5. Siegel R, Ward E, Brawley O, Jemal A. Cancer statistics, 2011: the impact of eliminating socioeconomic and racial disparities on premature cancer deaths. CA Cancer J Clin. 2011;61(4):212-236.

6. Walczak JR, Carducci MA. Prostate cancer: a practical approach to current management of recurrent disease. Mayo Clin Proc. 2007;82(2):243-249.

7. Chi KN, Bjartell A, Dearnaley D, et al. Castration-resistant prostate cancer: from new pathophysiology to new treatment targets. Eur Urol. 2009;56(4):594-605.

8. Sturge J, Caley MP, Waxman J. Bone metastasis in prostate cancer: emerging therapeutic strategies. Nat Rev Clin Oncol. 2011;8(6): 357-368.

9. Henshall SM, Quinn DI, Lee CS, et al. Altered expression of androgen receptor in the malignant epithelium and adjacent stroma is associated with early relapse in prostate cancer. Cancer Res. 2001;61(2): 423-427.

10. Massie CE, Lynch A, Ramos-Montoya A, et al. The androgen receptor fuels prostate cancer by regulating central metabolism and biosynthesis. EMBO J. 2011;30(13):2719-2733. 
11. National Comprehensive Cancer Network. Clinical practice guidelines in oncology: prostate cancer guidelines (version 2. 2011). 2011. Available from: http://www.nccn.org/professionals/physician_gls/f_guidelines. asp\#site. Accessed November 20, 2010.

12. Seruga B, Ocana A, Tannock IF. Drug resistance in metastatic castrationresistant prostate cancer. Nat Rev Clin Oncol. 2011;8(1):12-23.

13. Mostaghel EA, Page ST, Lin DW, et al. Intraprostatic androgens and androgen-regulated gene expression persist after testosterone suppression: therapeutic implications for castration-resistant prostate cancer. Cancer Res. 2007;67(10):5033-5041.

14. Montgomery RB, Mostaghel EA, Vessella R, et al. Maintenance of intratumoral androgens in metastatic prostate cancer: a mechanism for castrationresistant tumor growth. Cancer Res. 2008;68(11):4447-4454.

15. Efstathiou E, Logothetis CJ. A new therapy paradigm for prostate cancer founded on clinical observations. Clin Cancer Res. 2010;16(4):1100-1107.

16. Ang JE, Olmos D, de Bono JS. CYP17 blockade by abiraterone: further evidence for frequent continued hormone-dependence in castrationresistant prostate cancer. Br J Cancer. 2009;100(5):671-675.

17. de Bono JS, Logothetis CJ, Molina A, et al. Abiraterone and increased survival in metastatic prostate cancer. $N$ Engl J Med. 2011;364(21):1995-2005.

18. Tannock IF, de Wit R, Berry WR, et al. Docetaxel plus prednisone or mitoxantrone plus prednisone for advanced prostate cancer. $N \mathrm{Engl}$ J Med. 2004;351(15):1502-1512.

19. de Bono JS, Oudard S, Ozguroglu M, et al. Prednisone plus cabazitaxel or mitoxantrone for metastatic castration-resistant prostate cancer progressing after docetaxel treatment: a randomised open-label trial Lancet. 2010;376(9747):1147-1154.

20. Kantoff PW, Higano CS, Shore ND, et al. Sipuleucel-T immunotherapy for castration-resistant prostate cancer. $N$ Engl J Med. 2010;363(5):411-422.

21. Small EJ, de Bono JS. Prostate cancer: evolution or revolution? J Clin Oncol. 2011;29(27):3595-3598.

22. Josson S, Matsuoka Y, Chung LW, Zhau HE, Wang R. Tumor-stroma co-evolution in prostate cancer progression and metastasis. Semin Cell Dev Biol. 2010;21(1):26-32.

23. Joyce JA. Therapeutic targeting of the tumor microenvironment. Cancer Cell. 2005;7(6):513-520.

24. Tuxhorn JA, Ayala GE, Rowley DR. Reactive stroma in prostate cancer progression. J Urol. 2001;166(6):2472-2483.

25. Karlou M, Tzelepi V, Efstathiou E. Therapeutic targeting of the prostate cancer microenvironment. Nat Rev Urol. 2010;7(9):494-509.

26. Dudley AC, Shih SC, Cliffe AR, Hida K, Klagsbrun M. Attenuated p53 activation in tumour-associated stromal cells accompanies decreased sensitivity to etoposide and vincristine. $\mathrm{Br}$ J Cancer. 2008;99(1):118-125.

27. Hill R, Song Y, Cardiff RD, Van Dyke T. Selective evolution of stromal mesenchyme with p53 loss in response to epithelial tumorigenesis. Cell. 2005;123(6):1001-1011.

28. Kiaris H, Chatzistamou I, Trimis G, Frangou-Plemmenou M, Pafiti-KondiA, Kalofoutis A. Evidence for nonautonomous effect of p53 tumor suppressor in carcinogenesis. Cancer Res. 2005;65(5):1627-1630.

29. Johansson JE, Holmberg L, Johansson S, Bergstrom R, Adami HO. Fifteen-year survival in prostate cancer. A prospective, populationbased study in Sweden. JAMA. 1997;277(6):467-471.

30. Cunha GR, Hayward SW, Dahiya R, Foster BA. Smooth muscleepithelial interactions in normal and neoplastic prostatic development. Acta Anat (Basel). 1996;155(1):63-72.

31. Chung LW, Zhau HE, Ro JY. Morphologic and biochemical alterations in rat prostatic tumors induced by fetal urogenital sinus mesenchyme. Prostate. 1990;17(2):165-174.

32. Rowley DR. What might a stromal response mean to prostate cancer progression? Cancer Metastasis Rev. 1998-1999;17(4):411-419.

33. De Wever O, Demetter P, Mareel M, Bracke M. Stromal myofibroblasts are drivers of invasive cancer growth. Int J Cancer. 2008;123(10): 2229-2238.
34. Desmouliere A, Guyot C, Gabbiani G. The stroma reaction myofibroblast: a key player in the control of tumor cell behavior. Int $J$ Dev Biol. 2004;48(5-6):509-517.

35. Powell DW. Myofibroblasts: paracrine cells important in health and disease. Trans Am Clin Climatol Assoc. 2000;111:271-293.

36. Albini A, Sporn MB. The tumour microenvironment as a target for chemoprevention. Nat Rev Cancer. 2007;7(2):139-147.

37. Tuxhorn JA, Ayala GE, Smith MJ, Smith VC, Dang TD, Rowley DR. Reactive stroma in human prostate cancer: induction of myofibroblast phenotype and extracellular matrix remodeling. Clin Cancer Res. 2002;8(9):2912-2923

38. Barclay WW, Woodruff RD, Hall MC, Cramer SD. A system for studying epithelial-stromal interactions reveals distinct inductive abilities of stromal cells from benign prostatic hyperplasia and prostate cancer. Endocrinology. 2005;146(1):13-18.

39. Olumi AF, Grossfeld GD, Hayward SW, Carroll PR, Tlsty TD, Cunha GR. Carcinoma-associated fibroblasts direct tumor progression of initiated human prostatic epithelium. Cancer Res. 1999;59(19):5002-5011.

40. Hayashi N, Cunha GR. Mesenchyme-induced changes in the neoplastic characteristics of the Dunning prostatic adenocarcinoma. Cancer Res. 1991;51(18):4924-4930.

41. Miyake H, Hara I, Kurahashi T, Inoue TA, Eto H, Fujisawa M. Quantitative detection of micrometastases in pelvic lymph nodes in patients with clinically localized prostate cancer by real-time reverse transcriptase-PCR. Clin Cancer Res. 2007;13(4):1192-1197.

42. Bubendorf L, Schopfer A, Wagner U, et al. Metastatic patterns of prostate cancer: an autopsy study of 1589 patients. Hum Pathol. 2000;31(5):578-583.

43. Cheng L, Bergstralh EJ, Cheville JC, et al. Cancer volume of lymph node metastasis predicts progression in prostate cancer. Am J Surg Pathol. 1998;22(12):1491-1500.

44. Pontes-Junior J, Reis ST, Dall'Oglio M, et al. Evaluation of the expression of integrins and cell adhesion molecules through tissue microarray in lymph node metastases of prostate cancer. J Carcinog. 2009;8:3.

45. Hay ED. An overview of epithelio-mesenchymal transformation. Acta Anat (Basel). 1995;154(1):8-20.

46. Guarino M, Rubino B, Ballabio G. The role of epithelial-mesenchymal transition in cancer pathology. Pathology. 2007;39(3):305-318.

47. Datta K, Muders M, Zhang H, Tindall DJ. Mechanism of lymph node metastasis in prostate cancer. Future Oncol. 2010;6(5):823-836.

48. Cao Y. Opinion: emerging mechanisms of tumour lymphangiogenesis and lymphaticmetastasis. Nat Rev Cancer. 2005;5(9):735-743.

49. Koeneman KS, Yeung F, Chung LW. Osteomimetic properties of prostate cancer cells: a hypothesis supporting the predilection of prostate cancer metastasis and growth in the bone environment. Prostate. 1999;39(4):246-261.

50. Lecrone V, Li W, Devoll RE, Logothetis C, Farach-Carson MC. Calcium signals in prostate cancer cells: specific activation by bone-matrix proteins. Cell Calcium. 2000;27(1):35-42.

51. Thomas R, True LD, Bassuk JA, Lange PH, Vessella RL. Differential expression of osteonectin/SPARC during human prostate cancer progression. Clin Cancer Res. 2000;6(3):1140-1149.

52. Castellano D, Sepulveda JM, Garcia-Escobar I, RodriguezAntolin A, Sundlov A, Cortes-Funes H. The role of RANK-ligand inhibition in cancer: the story of denosumab. Oncologist. 2011;16(2): $136-145$.

53. Keller ET, Brown J. Prostate cancer bone metastases promote both osteolytic and osteoblastic activity. J Cell Biochem. 2004;91(4): 718-729.

54. Lang SH, Miller WR, Habib FK. Stimulation of human prostate cancer cell lines by factors present in human osteoblast-like cells but not in bone marrow. Prostate. 1995;27(5):287-293.

55. Blaszczyk N, Masri BA, Mawji NR, et al. Osteoblast-derived factors induce androgen-independent proliferation and expression of prostatespecific antigen in human prostate cancer cells. Clin Cancer Res. 2004;10(5):1860-1869. 
56. Li Y, Sikes RA, Malaeb BS, et al. Osteoblasts can stimulate prostate cancer growth and transcriptionally down-regulate PSA expression in cell line models. Urol Oncol. 2011;29(6):802-808.

57. Sung SY, Hsieh CL, Law A, et al. Coevolution of prostate cancer and bone stroma in three-dimensional coculture: implications for cancer growth and metastasis. Cancer Res. 2008;68(23):9996-10003.

58. Lu Y, Zhang J, Dai J, et al. Osteoblasts induce prostate cancer proliferation and PSA expression through interleukin-6-mediated activation of the androgen receptor. Clin Exp Metastasis. 2004;21(5):399-408.

59. Reichert JC, Quent VM, Burke LJ, Stansfield SH, Clements JA, Hutmacher DW. Mineralized human primary osteoblast matrices as a model system to analyse interactions of prostate cancer cells with the bone microenvironment. Biomaterials. 2010;31(31):7928-7936.

60. Parker C, Heinrich D, O'Sullivan JM, et al. Overall survival benefit of radium-223 chloride (Alpharadin ${ }^{\mathrm{TM}}$ ) in the treatment of patients with symptomatic bone metastases in castration-resistant prostate cancer (CRPC): a phase III randomized trial (ALSYMPCA). Paper presented at: 2011 European Multidisciplinary Cancer Congress; September 24-27, 2011; Stockholm, Sweden.

61. Bissell MJ, Radisky D. Putting tumours in context. Nat Rev Cancer. 2001;1(1):46-54.

62. Goel HL, Li J, Kogan S, Languino LR. Integrins in prostate cancer progression. Endocr Relat Cancer. 2008;15(3):657-664.

63. Mitra SK, Schlaepfer DD. Integrin-regulated FAK-Src signaling in normal and cancer cells. Curr Opin Cell Biol. 2006;18(5):516-523.

64. Thalmann GN, Rhee H, Sikes RA, et al. Human prostate fibroblasts induce growth and confer castration resistance and metastatic potential in LNCaP Cells. Eur Urol. 2010;58(1):162-171.

65. Abate-Shen C, Shen MM. FGF signaling in prostate tumorigenesis new insights into epithelial-stromal interactions. Cancer Cell. 2007;12(6):495-497.

66. Dutt SS, Gao AC. Molecular mechanisms of castration-resistant prostate cancer progression. Future Oncol. 2009;5(9):1403-1413.

67. Pienta KJ, Bradley D. Mechanisms underlying the development of androgen-independent prostate cancer. Clin Cancer Res. 2006;12(6):1665-1671.

68. Antonarakis ES, Armstrong AJ. Evolving standards in the treatment of docetaxel-refractory castration-resistant prostate cancer. Prostate Cancer Prostatic Dis. 2011;14(3):192-205.

69. Sternberg CN, Dumez H, Van Poppel H, et al. Docetaxel plus oblimersen sodium (Bcl-2 antisense oligonucleotide): an EORTC multicenter, randomized phase II study in patients with castration-resistant prostate cancer. Ann Oncol. 2009;20(7):1264-1269.

70. Carducci MA, Saad F, Abrahamsson PA, et al. A phase 3 randomized controlled trial of the efficacy and safety of atrasentan in men with metastatic hormone-refractory prostate cancer. Cancer. 2007;110(9):1959-1966.

71. Vishnu P, Tan WW. Update on options for treatment of metastatic castration-resistant prostate cancer. Onco Targets Ther. 2010;3:39-51.

72. AstraZeneca halts phase III trial of ZIBOTENTAN in non-metastatic castrate resistant prostate cancer [press release]. London: AstraZeneca; February 7, 2011.

73. Fizazi K, Carducci M, Smith M, et al. Denosumab versus zoledronic acid for treatment of bone metastases in men with castration-resistant prostate cancer: a randomised, double-blind study. Lancet. 2011; 377(9768):813-822.

74. Fizazi K. The role of Src in prostate cancer. Ann Oncol. 2007; 18(11):1765-1773.

75. Saad F. Src as a therapeutic target in men with prostate cancer and bone metastases. BJU Int. 2009;103(4):434-440.

76. Mendiratta P, Mostaghel E, Guinney J, et al. Genomic strategy for targeting therapy in castration-resistant prostate cancer. J Clin Oncol. 2009;27(12):2022-2029.

77. Araujo JC, Mathew P, Armstrong AJ, et al. Dasatinib combined with docetaxel for castration-resistant prostate cancer: results from a phase 1-2 study. Cancer. 2012;118(1):63-71.
78. Bristol-Myers Squibb. Randomized study comparing docetaxel plus dasatinib to docetaxel plus placebo in castration-resistant prostate cancer (READY). In: ClinicalTrials gov [website on the Internet]. Bethesda, MD: US National Library of Medicine; 2008 [updated April 30, 2012]. Available from: http://clinicaltrials.gov/show/NCT00744497. NLM Identifier: NCT00744497. Accessed December 21, 2011.

79. Danielpour D. Functions and regulation of transforming growth factorbeta (TGF-beta) in the prostate. Eur J Cancer. 2005;41(6):846-857.

80. Bhowmick NA, Chytil A, Plieth D, et al. TGF-beta signaling in fibroblasts modulates the oncogenic potential of adjacent epithelia. Science. 2004;303(5659):848-851.

81. Jones E, Pu H, Kyprianou N. Targeting TGF-beta in prostate cancer: therapeutic possibilities during tumor progression. Expert Opin Ther Targets. 2009;13(2):227-234.

82. Verona EV, Elkahloun AG, Yang J, Bandyopadhyay A, Yeh IT, Sun LZ. Transforming growth factor-beta signaling in prostate stromal cells supports prostate carcinoma growth by up-regulating stromal genes related to tissue remodeling. Cancer Res. 2007;67(12):5737-5746.

83. Song K, Wang H, Krebs TL, Kim SJ, Danielpour D. Androgenic control of transforming growth factor-beta signaling in prostate epithelial cells through transcriptional suppression of transforming growth factor-beta receptor II. Cancer Res. 2008;68(19):8173-8182.

84. Mueller MM, Fusenig NE. Friends or foes - bipolar effects of the tumour stroma in cancer. Nat Rev Cancer. 2004;4(11):839-849.

85. Mackay HJ, Buckanovich RJ, Hirte H, et al. A phase II study single agent of aflibercept (VEGF Trap) in patients with recurrent or metastatic gynecologic carcinosarcomas and uterine leiomyosarcoma. A trial of the Princess Margaret Hospital, Chicago and California Cancer Phase II Consortia. Gynecol Oncol. 2012;125(1):136-140.

86. Colombo N, Mangili G, Mammoliti S, et al. A phase II study of aflibercept in patients with advanced epithelial ovarian cancer and symptomatic malignant ascites. Gynecol Oncol. 2012;125(1):42-47.

87. de Groot JF, Lamborn KR, Chang SM, et al. Phase II study of aflibercept in recurrent malignant glioma: a North American Brain Tumor Consortium study. J Clin Oncol. 2011;29(19):2689-2695.

88. Twardowski P, Stadler WM, Frankel P, et al. Phase II study of aflibercept (VEGF-Trap) in patients with recurrent or metastatic urothelial cancer, a California Cancer Consortium Trial. Urology. 2010;76(4):923-926.

89. Sanofi-Aventis; Regeneron Pharmaceuticals. Aflibercept in combination with docetaxel in metastatic androgen independent prostate cancer (VENICE). In: ClinicalTrials.gov [website on the Internet]. Bethesda, MD: US National Library of Medicine. 2007 [updated April 30, 2012]. Available from: http://clinicaltrials.gov/show/NCT00519285. NLM Identifier: NCT00519285. Accessed December 21, 2011.

90. Van Cutsem E, Tabernero J, Lakomy R, et al. Intravenous (IV) aflibercept versus placebo in combination with irinotecan/5-FU (FOLFIRI) for second-line treatment of metastatic colorectal cancer (mCRC): results of a multinational phase III trial (EFC10262-VELOUR) [abstract]. Ann Oncol. 2011;22(Suppl 5):v18.

91. Van Cutsem E, Prenen H, Guillen-Ponce C, et al. A phase I/II, openlabel, randomised study of BIBF 1120 plus mFOLFOX6 compared to bevacizumab plus mFOLFOX6 in patients with metastatic colorectal cancer. Paper presented at: 2011 European Multidisciplinary Cancer Congress; 2011 September 23-27; Stockholm, Sweden.

92. Adelerg D, Karakunnel JJ, Gulley JL, et al. A phase II study of cediranib in post-docetaxel castration-resistant prostate cancer. Paper presented at: American Society of Clinical Oncology 2010 Genitourinary Cancers Symposium; March 5-7, 2010; San Francisco, CA.

93. Dalgleish A, Galustian C. The potential of immunomodulatory drugs in the treatment of solid tumors. Future Oncol. 2010;6(9):1479-1484.

94. Celgene to discontinue docetaxel and prednisone plus lenalidomide phase III trial on CRPC [press release]. Boudry: Celgene International Sarl; November 23, 2011.

95. Zarnegar R, Michalopoulos GK. The many faces of hepatocyte growth factor: from hepatopoiesis to hematopoiesis. J Cell Biol. 1995;129(5):1177-1180. 
96. Peruzzi B, Bottaro DP. Targeting the c-Met signaling pathway in cancer. Clin Cancer Res. 2006;12(12):3657-3660.

97. Jiang WG. Hepatocyte growth factor and the hepatocyte growth factor receptor signalling complex as targets in cancer therapies. Curr Oncol. 2007;14(2):66-69.

98. Cao B, Su Y, Oskarsson M, et al. Neutralizing monoclonal antibodies to hepatocyte growth factor/scatter factor (HGF/SF) display antitumor activity in animal models. Proc Natl Acad Sci U S A. 2001;98(13):7443-7448.

99. Dai Y, Siemann DW. BMS-777607, a small-molecule met kinase inhibitor, suppresses hepatocyte growth factor-stimulated prostate cancer metastatic phenotype in vitro. Mol Cancer Ther. 2010;9(6):1554-1561.

100. Hussain M, Smith MR, Sweeney C, et al. Cabozantinib (XL184) in metastatic castration-resistant prostate cancer (mCRPC): results from a phase II randomized discontinuation trial [abstract]. J Clin Oncol. 2011;29 Suppl:4516.

101. Di Lorenzo G, Buonerba C, Kantoff PW. Immunotherapy for the treatment of prostate cancer. Nat Rev Clin Oncol. 2011;8(9):551-561.

102. Bander NH, Yao D, Liu H, et al. MHC class I and II expression in prostate carcinoma and modulation by interferon-alpha and -gamma. Prostate. 1997;33(4):233-239.
103. Yang L, Pang Y, Moses HL. TGF-beta and immune cells: an important regulatory axis in the tumor microenvironment and progression. Trends Immunol. 2010;31(6):220-227.

104. Mercader M, Bodner BK, Moser MT, et al. T cell infiltration of the prostate induced by androgen withdrawal in patients with prostate cancer. Proc Natl Acad Sci U S A. 2001;98(25):14565-14570.

105. MD Anderson Cancer Center; Bristol-Myers Squibb. Ipilimumab + androgen deprivation therapy in prostate cancer. In: ClinicalTrials. gov [website on the Internet]. Bethesda, MD: US National Library of Medicine. 2011 [updated April 11, 2012]. Available from: http://clinicaltrials.gov/show/NCT01377389. NLM Identifier: NCT01377389. Accessed December 21, 2011.

106. OHSU Knight Cancer Institute; National Cancer Institute. Ipilimumab in combination with androgen suppression therapy in treating patients with metastatic hormone-resistant prostate cancer. In: ClinicalTrials.gov [website on the Internet]. Bethesda, MD: US National Library of Medicine. 2011 [updated March 22, 2012]. Available from: http://clinicaltrials.gov/show/NCT01498978. NLM Identifier: NCT01498978. Accessed December 21, 2011
Cancer Management and Research

\section{Publish your work in this journal}

Cancer Management and Research is an international, peer-reviewed open access journal focusing on cancer research and the optimal use of preventative and integrated treatment interventions to achieve improved outcomes, enhanced survival and quality of life for the cancer patient The journal welcomes original research, clinical \& epidemiological

\section{Dovepress}

studies, reviews \& evaluations, guidelines, expert opinion \& commentary, case reports \& extended reports. The manuscript management system is completely online and includes a very quick and fair peerreview system, which is all easy to use. Visit http://www.dovepress.com/ testimonials.php to read real quotes from published authors. 